\title{
Physical-Chemical Characteristics of Cutin Separated from Tomato Waste for the Preparation of Bio-lacquers
}

\author{
A. Cifarelli, I. M. Cigognini, L. Bolzoni, A. Montanari \\ Experimental Station for the Food Preserving Industry, Tanara Street, Parma, 43122, Italy. \\ E-mail: angelica.cifarelli@cococo.ssica.it; angela.montanari@ssica.it
}

\begin{abstract}
Green chemistry protocols are proposed to produce high-value chemicals from waste tomatoes. Longchain hydroxy fatty acids (called cutin acids), in particular the 10,16-dihydroxyhexadecanoic acid and its oligomers, could be innovative building-block chemicals for the synthesis of novel bio-resins and lacquers suitable as internal protective coating for metal food packaging. However, these natural compounds are not currently commercially available. This study investigates the possibility of extracting cutin acids from tomato peels without the use of organic solvents and by an efficient, cost-effective, and environmentally safe method amenable to industrial scale-up. The first route investigated was based on alkaline hydrolysis of the tomato cuticle. The second involved the acid free-selective precipitation of cutin. Finally, cutin was isolated by hydrogen peroxide-assisted hydrolysis. GC-MS analysis revealed the main chemical compound isolated by all methods to be 10,16dihydroxyhexadecanoic acid, the principal component of tomato cutin, with extraction yields ranging from 81 to $96 \%$. Products are different in terms of appearance, solubility, the degree of crosslinking observed and molecular weight, as shown by GPC analysis. Furthermore, the products extracted were characterized by means of FT-IR spectroscopy and thermal analysis. The cutin obtained through alkaline hydrolysis results the best raw material for bio-resin preparation.
\end{abstract}

Keywords: organic natural compounds, tomato waste, FT-IR spectroscopy, thermal analysis.

\section{Introduction}

The food industry produces large volumes of by-products resulting from the preparation of a variety of tomato products [1]. Tomato processing by-products represent $5-13 \%$ of tomato production as a whole [2]. The valorisation of agro-industrial waste is a key technology that contributes to the development of sustainable processes, the generation of value-added products and the creation of a circular economy. Solid waste from the tomato industry, in particular tomato peels, are currently used in the zoo-technical sector as animal feed, or as the substrate for fertilizer and biogas production. Numerous studies have also looked at the extraction of food additives or ingredients from tomato waste for use in cosmetics (carotenoids, essential oils, etc.) [3].

The tissue in tomato peel is a highly structured material: a complex mixture of polyesters associated with waxes -with a very small reactivity - that contains cutin, fatty acids, polysaccharides (mainly cellulose), polypeptides, phenolic compounds, lycopene as well as several minor carotenoids, ash and minerals. Cutin is the main component (between $40 \%$ and $85 \%$, w/w) of the plant cuticle and plays an important role as a structural component and defensive barrier against pathogens, as well as in protecting against uncontrolled water loss. From a chemical point of view, cutin is defined as a polymeric network of C16 and C18 polyhydroxylated fatty acids that are crosslinked by ester bonds [4]. An interesting opportunity is to use tomato peels as the raw material for extracting valueadded products not commercially available as standardized tomato extracts, such as 10,16- dihydroxyhexadecanoic acid (and its oligomers). Long chain hydroxy acids are peculiarly reactive polyfunctional compounds, and are currently being used in the pharmaceutical industry, and as monomers for synthesising adhesives [5] and lacquers [6]. Although cutin extraction methods exist in the literature [7], organic solvent-free procedures, known for their high extraction yields, are scant or absent, particularly involving the use of tomato by-products as the raw material.

Inexpensive and environmentally friendly reactants should be favoured in order to develop feasible and sustainable extraction processes in terms of environmental and economic impact. This study aimed to identify methods that, without the use of organic solvents and under mild conditions, would provide: the effective depolymerisation of the species in question; the degradation of the compact lignocellulosic skeleton of tomato peel tissue [8]; and high-purity end products. Previous studies [9] showed that the action of hydrogen peroxide at a $\mathrm{pH}$ higher than 7 can generate an extremely nucleophilic species, mainly oxidising radicals, e.g. hydroperoxide ion $\left(\mathrm{HOO}^{-}\right)$, which dominate under alkaline conditions $(\mathrm{pH}=11.6)$. In light of the previous literature, we hypothesized that the addition of peroxide to the reaction mixture would significantly enhance cell wall disruption, cutin depolymerisation, and lignin hydrolysis, due to the cleavage of $\alpha$-aryl ether linkage in a guaiacyl-type lignin, by means of a Dakin-like mechanism in an alkaline solution [10]. 
Therefore, this study had the objective of comparing a cutin extraction method that was already known [11] to innovative processes which were capable of inducing different degrees of depolymerisation in a cross-linked polyester network, and of degrading interfering compounds, for the purpose of finding a more selective 10,16dihydroxyesadecanoic acid extraction method. Cutin was first isolated by means of a saponification reaction with $\mathrm{NaOH}$. An alternative route was investigated involving the coprecipitation of all hydrolysable compounds in the tomato cuticle. The other method used hydrogen peroxide-assisted alkaline hydrolysis (the $\mathrm{NaOH} / \mathrm{H}_{2} \mathrm{O}_{2} \mathrm{route}$ ). Finally, cutin was isolated in the form of sodium carboxylate by acid-free selective precipitation.

\section{Materials and methods}

\subsection{Reagents}

Tomato peel (TP) from the tomato processing industry was collected from local tomato processors in Parma, Italy. About $10 \mathrm{~kg}$ of TP was used in the experiments. Reagents and solvents were used as received without further purification: sodium hydroxide ( $\mathrm{NaOH}$, beads, VWR), hydrochloric acid ( $\mathrm{HCl}, 37 \%$, ACS GR, , VWR), hydrogen peroxide (H2O2, 40\% w/v solution, GR ACS, Carlo Erba), Tetrahydrofuran (THF, anhydrous, $\geq 99.9 \%$, SimaAldrich), ethanol ( $\geq 98.9 \%$, Fluka), Dowanol PMA ( $\geq 99.5 \%$, Sigma-Aldrich), Methyl isobutyl ketone (MIBK, ACS reagent $98.5 \%$ Sigma-Aldrich), butyl glycol ( $\geq 99.5 \%$, Sigma-Aldrich), tert-butyl methyl ether (for gas chromatography, SupraSolv), dichlormethan Pestanal@ stabilised with amylene (approx. 25 mg/L), dichloromethane, $\mathrm{CH} 2 \mathrm{Cl} 2$ for analysis, Riedel-deHaën), methanol anhydrous ( $\geq 99.8 \%$, Sigma-Aldrich), sodium sulphate anhydrous ( $\geq 99.0 \%$, Sigma-Aldrich), N,O-bis (trimethylsilyl)trifluoro-acetamide (BSTFA, 99\%) with trimethylchlorosilane (TMCS, 1\%) (Sigma-Aldrich), sodium cube in mineral oil (99.9\%, Aldrich), pyridine RPEACS ( $\geq 99.6 \%$, Carlo Erba), sulphuric acid ACS reagent (95.0-98.0\%, Sigma-Aldrich).

\subsection{Cutin isolation}

Cutin was isolated from tomato peels (TP) by different extraction procedures: alkaline hydrolysis (method A); the recovery of cutin as sodium carboxylate (method B); the coprecipitation of all hydrolysable compounds in the tomato cuticle (method $\mathrm{Ac}$ ); and, finally, a sodium hydroxide/hydrogen peroxide $\left(\mathrm{NaOH} / \mathrm{H}_{2} \mathrm{O}_{2}\right)$ route (method C).

The procedures A, Ac and B involved a first step consisting in thermally treating tomato peels (100g) with 3 $\% \mathrm{NaOH}(400 \mathrm{~mL})$ at $130^{\circ} \mathrm{C}$ for 15 minutes, removing spent skins, and filtering the dark brown solution to eliminate residual pulp. The second step for method A involved the centrifugation of the solution ( $\mathrm{pH} 12.8)$ to eliminate suspended solids, followed by acidification with $\mathrm{HCl}$ fuming $37 \%$ up to $\mathrm{pH} 4-4.5$ at $20^{\circ} \mathrm{C}$. Then, the gummy residue was obtained by centrifugation and washed until acid free. Conversely, in method Ac, the coprecipitation of all components soluble under alkaline conditions was carried out. In method B, the cutin was separated out as sodium carboxylate from an alkaline solution by means of filtration or centrifugation. The residues were solubilized in water and then restored to $\mathrm{pH}$ 4-4.5.

In the $\mathrm{NaOH} / \mathrm{H}_{2} \mathrm{O}_{2}$ route (method $\mathrm{C}$ ), the tomato peels were treated with an aqueous solution of hydrogen peroxide $\left(\mathrm{H}_{2} \mathrm{O}_{2}, 4 \% \mathrm{~V} / \mathrm{V}\right)$, with the $\mathrm{pH}$ adjusted to 12.8 using $\mathrm{NaOH}$ at $90^{\circ} \mathrm{C}$ for $1 \mathrm{~h}$; then the spent skins were removed from the alkaline solution. $\mathrm{Next}, \mathrm{HCl}(5 \% \mathrm{p} / \mathrm{p})$ was added to the light brown solution at room temperature, as before, and the pale-yellow solid was collected. The visual analysis of extracted cutin samples was carried out. The reaction yield values, calculated for all methods, were based on the original TP in \% and were corrected for the dry residue value. The mean values, reported in section 3.1, were calculated by repeating the whole experiment independently several times.

\subsection{Assay of water content and solubility}

The water content was determined gravimetrically using an analytical balance (Sartorius, Germany). The samples were dried in an oven (Fratelli Galli, Italy) at $105^{\circ} \mathrm{C}$ for $2 \mathrm{~h}$ and then weighed (Official Gazette of the Italian Republic - General series-n. 137 Annex-B 2012). The analysis was performed in triplicate at least. Dry residue (DR) was expressed as \% dry matter (g dry sample $100 / \mathrm{g}$ wet sample).

The solubility of each cutin sample $(10 \mathrm{~g})$ was evaluated at room temperature $\left(20^{\circ} \mathrm{C}\right)$. Ultrasonic agitation (for 30 minutes) was used to facilitate solid aggregate dissolution. The solid residue remaining after solubilisation was separated by centrifugation $\left(4,500 \mathrm{RPM} \mathrm{X} 30 \mathrm{~min}\right.$ at $\left.20^{\circ} \mathrm{C}\right)$, dried by means of $\mathrm{N}_{2}$ flow and weighed. The amount of soluble material was calculated by subtracting the residue weight from that of the initial cutin (data corrected for dry residue). The solubility assay was carried out in triplicate at least. Each extract represented a replication in the trial.

\subsection{FT-IR Spectroscopy}

Fourier-transform infrared spectroscopy (FT-IR) spectra were recorded on a Perkin-Elmer FT-IR Spectrum One spectrometer, equipped with Spectrum v5.3.1 software. The FT-IR spectra were recorded in the 4000-600 
$\mathrm{cm}^{-1}$ range, at a resolution of $4 \mathrm{~cm}^{-1}$; after 16 scans for each spectrum, the spectrum average calculation was based on at least three replications.

\subsection{GC-MS Analysis}

The cutin monomers in each sample were identified by GC-MS analysis as either methyl esters or TMSi esters formed by $\mathrm{NaOCH}_{3}$-catalyzed methanolysis, as in the procedure previously reported in the literature [12].

GC-MS analysis on methanolysates cutin samples was performed using the Varian 450 GC gas chromatograph (Walnut Creek, CA, USA) coupled with Varian 300 MS mass spectrometry (Walnut Creek, CA, USA). The compounds were separated on a ZB-Semivolatiles, Celona, PA, USA) (30 m X $0.25 \mathrm{~mm} \varnothing, 0.25 \mu \mathrm{m}$ film thickness, Phenomenex), under the following GC conditions: injector temperature $300^{\circ} \mathrm{C}$; mass transfer line temperature $300^{\circ} \mathrm{C}$; oven temperature program $125^{\circ} \mathrm{C}$ (starting temperature); rate of $5^{\circ} \mathrm{C} / \mathrm{min}$ up to $205^{\circ} \mathrm{C}(10 \mathrm{~min})$; subsequent rate of $5^{\circ} \mathrm{C} / \mathrm{min}$ up to $300^{\circ} \mathrm{C}(5 \mathrm{~min})$; flux $1 \mathrm{~mL} / \mathrm{min}$. The MS source temperature was $330^{\circ} \mathrm{C}$. The analysis was carried out under full-scan acquisition within an a.m.u range of 50-600. The software Bruker MS Workstation version 7.0 was used. The eluted compounds were identified using the Wiley or NIST library. Identification certainty was given by a probability factor (\%) and by the Match Factor (F.M.). Cutin composition was calculated from the integrated areas of the corresponding peaks in the GC-MS ion chromatograms. The cutin monomer yield was determined gravimetrically as $\mathrm{CHCl}_{2}$-soluble material and corrected for the dry residue value [13].

\subsection{Gel permeation chromatography (GPC)}

The GPC system comprised a WATERS 1525 pump equipped with a WATERS 2414 IR detector and a chromatographic SEC column 4.6 X $300 \mathrm{~mm}$ particle size $5 \mu \mathrm{m}$ (Phenomenex, USA). The solvent used was tetrahydrofuran. GPC analysis was performed under the following conditions: flow $0.3 \mathrm{ml} / \mathrm{min}$, pressure $1600 \mathrm{PSI}$, and temperature $35^{\circ} \mathrm{C}$. The column calibration was obtained with polystyrene standards. Weight averaged (Mw) and number-averaged $(\mathrm{Mn})$ molecular weights, along with polydispersity $\left(\mathrm{P}=\mathrm{MwMn}{ }^{-1}\right)$, were calculated as described elsewhere [14]. Unipoint Gilson Software was used to record and process chromatograms. Only fully dissolved parts of the sample were analysed by GPC. The experiments were performed in triplicate. Each extract represented a replication in the trial.

\subsection{Thermogravimetric analysis (TGA)}

Thermogravimetric analysis (TGA) was performed on samples (6-8 mg) by means of a Perkin-Elmer thermogravimetric analyser Pyris 1 TGA instrument, using a temperature program of 25 to $600^{\circ} \mathrm{C}$ at a heating rate of $10^{\circ} \mathrm{Cmin}^{-1}$ under $\mathrm{N}_{2}\left(24 \mathrm{mLmin}^{-1}\right)$. The onset temperature (T onset), maximum decomposition temperature (Td, $\max$ ), weight of solid residue remaining at $600^{\circ} \mathrm{C}$, weight loss $(\Delta \mathrm{W})$ and derivative thermograms (DTG) were analysed using Pyris v8 software. The experiments were performed in triplicate. Each extract represented a replication in the trial.

\subsection{Differential scanning calorimetry (DSC)}

3-4 mg of each sample was weighed separately and subjected to thermal scans using a DSC (Pyris 8000 DSC, Perkin Elmer, USA). Prior to taking the measurements, the DSC was calibrated using indium (melting onset temperature $156.6 \pm 0.8^{\circ} \mathrm{C}, \Delta \mathrm{H}=28.4 \pm 0.7 \mathrm{~J} / \mathrm{g}$ ). Two sets of experiments were performed using two different type of pans: aluminium pans of $50 \mu \mathrm{L}$ with pierced lids; and stainless-steel sample containers sealed with O-rings.

In the first case, the following thermal profile was used: isotherm at $-60^{\circ} \mathrm{C}$ for $2 \mathrm{~min}$, with repeated heatingcooling cycling from $60^{\circ} \mathrm{C}$ to $150^{\circ} \mathrm{C}$ at a heating rate of $10^{\circ} \mathrm{C} / \mathrm{min}$.

The other set of experiments was performed using a limited thermal profile by O-ring glass transition: from $5^{\circ} \mathrm{C}$ to $150^{\circ} \mathrm{C}$ at a heating rate of $10^{\circ} \mathrm{C} / \mathrm{min}$, for repeated heating-cooling cycling measurements.

The reference used during the analysis was an empty pan. The experiments were performed in triplicate. The glass transition temperature at the midpoint of the change in heat capacity (Tg,m), the onset and peak temperatures ( $\left.T_{\text {ONSET }}, T_{p}\right)$, the change in enthalpy $(\Delta \mathrm{H})$, and the change in specific heat capacity due to glass transition $(\Delta \mathrm{Cp})$ were calculated using the DSC software (Pyris Software v11.0 USA).

\subsection{Melt-condensation of cutin}

Polyester films from each cutin extraction method were prepared by means of melt-polycondensation at a high temperature $\left(150^{\circ} \mathrm{C}\right)$ directly into the air: approx. $300 \mathrm{mg}$ of the different extracted products were placed in open glass petri dishes ( $30 \times 30 \mathrm{~mm}^{2}$ and $0.1 \mathrm{~mm}$ deep) and heated in an oven at $150^{\circ} \mathrm{C}$ for different periods of time (from 2h-8h).

\section{Results and discussion}




\subsection{Extraction yields and properties of cutin.}

The extraction procedures investigated (A, B and C methods) showed significant differences in terms of reaction yield. The reaction yield obtained using methods $A(18 \pm 3 \%)$ and $A c(20 \pm 5 \%)$ were much higher than the yield produced using method $B(9 \pm 2 \%)$, because method $B$ required the selective collection of solid residue, separated out from a supersaturated alkaline solution.

The reaction yield produced using method $C$ was $5 \pm 1 \%$, i.e. significantly lower than methods $A$ and Ac. This may be due both to the selectivity of the hydrogen peroxide-route and to the incomplete collection of cutin $\mathrm{C}$ by filtration, owing to its solubility in water. The gummy mass, obtained from methods A and Ac (figure1), is a sticky mass at room temperature. Sticky, clinging, golden-coloured films were produced by creating thin layers of products A and Ac. The products obtained by methods B and C, however, dried easily into crystalline solids, yellow and pale yellow in colour respectively, and did not form films through water evaporation (figure 1).

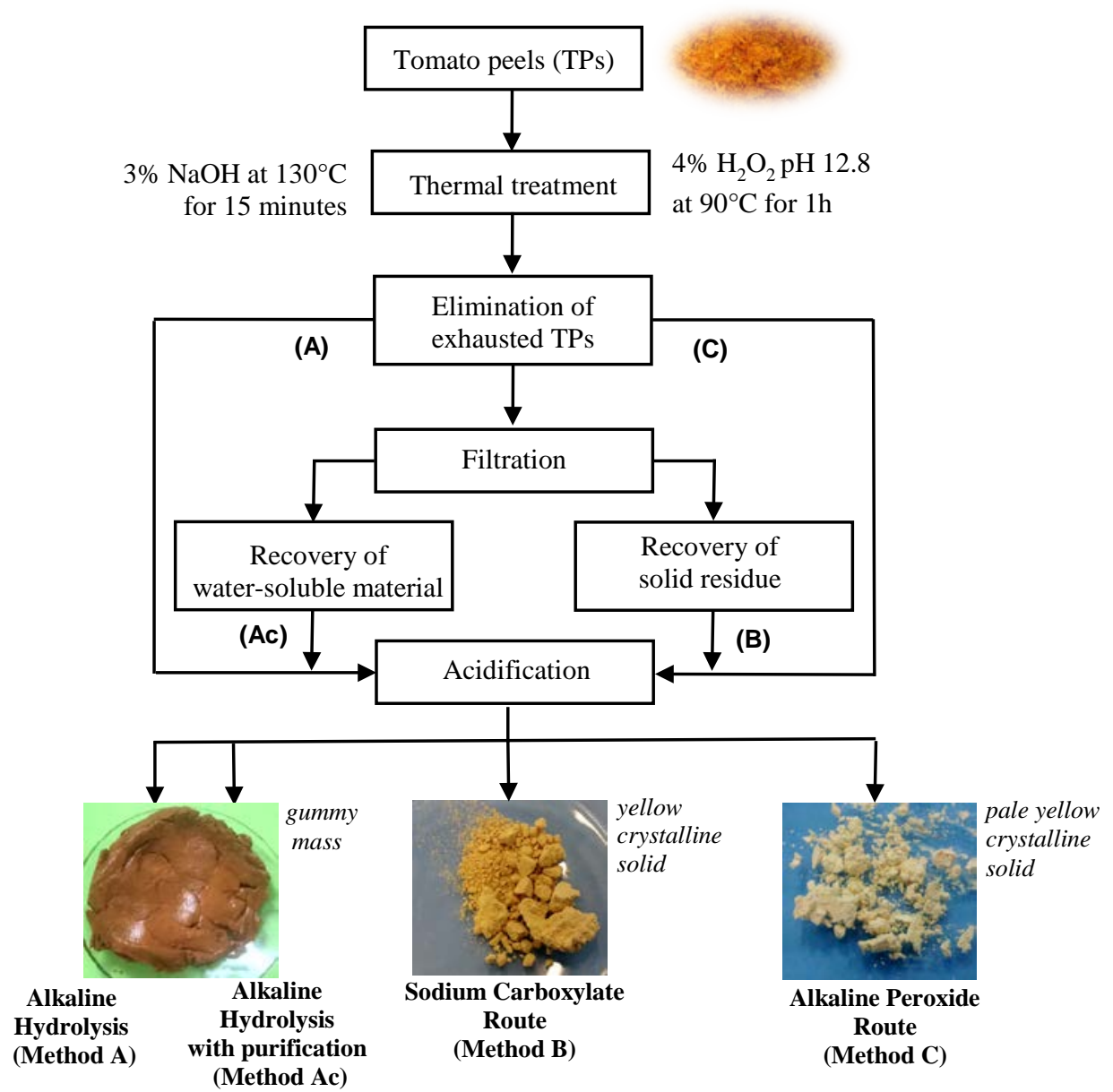

Figure 1. Schematic flow chart of tested protocols for the isolation of tomato cutin

\subsection{FT-IR spectra}

The FT-IR spectra of cutin samples extracted by methods B (figure 2c-left) and C (figure 2d-left) showed the characteristic bands of hydroxy acids [15]. The main bands are listed in table 1. The broad, intense band at 3300 $\mathrm{cm}^{-1}$ was ascribed to the stretching of hydrogen-bonded hydroxyl groups $v(\mathrm{OH})$. The sharp, intense band at 1702 $\mathrm{cm}^{-1}$ and the shoulders at 1706 and $1693 \mathrm{~cm}^{-1}$ were assigned to carbonyl stretching in carboxylic acid.

The infrared spectra of cutin extracted by methods Ac (figure 2a-left) and A (figure 2b-left) showed significant differences to the FT-IR spectra of samples B and C.

Considering the frequencies of the carbonyl stretching, the FT-IR spectra of sample A and Ac displayed a main band at $1712 \mathrm{~cm}^{-1}$ assigned to carbonyls in a loosely packed polyester phase as well as to ester groups interacting with residual hydroxyls by H-bonding [16]. This band was not found in the FT-IR spectra of samples B and C. Moreover, shoulders on the $v(\mathrm{C}=\mathrm{O})$ band at $1712 \mathrm{~cm}^{-1}$ were identified, at 1693 and $1704 \mathrm{~cm}^{-1}$ in particular, and ascribed to carbonyl stretching in carboxylic acid; and at $1728 \mathrm{~cm}^{-1}$, ascribed to ester.

Therefore, the FT-IR analysis showed that samples A and Ac consist of a mixture of acids and esters and that they have a certain esterification degree, missing in samples B and C. 
In addition, the FT-IR spectra of samples A and Ac presented bands ascribed to double bonds in aliphatic compounds $\left(1640 \mathrm{~cm}^{-1}\right)$ and in phenolic acids $\left(1632 \mathrm{~cm}^{-1}\right)$. Both spectra showed bands at $1606 \mathrm{~cm}^{-1}$ and at 835 $\mathrm{cm}^{-1}$ that confirmed the presence of aromatics (table 1). In addition, bands corresponding to aromatic compounds conjugated with $\mathrm{C}=\mathrm{C}$ were found at 1559,1515 and $1450 \mathrm{~cm}^{-1}$.

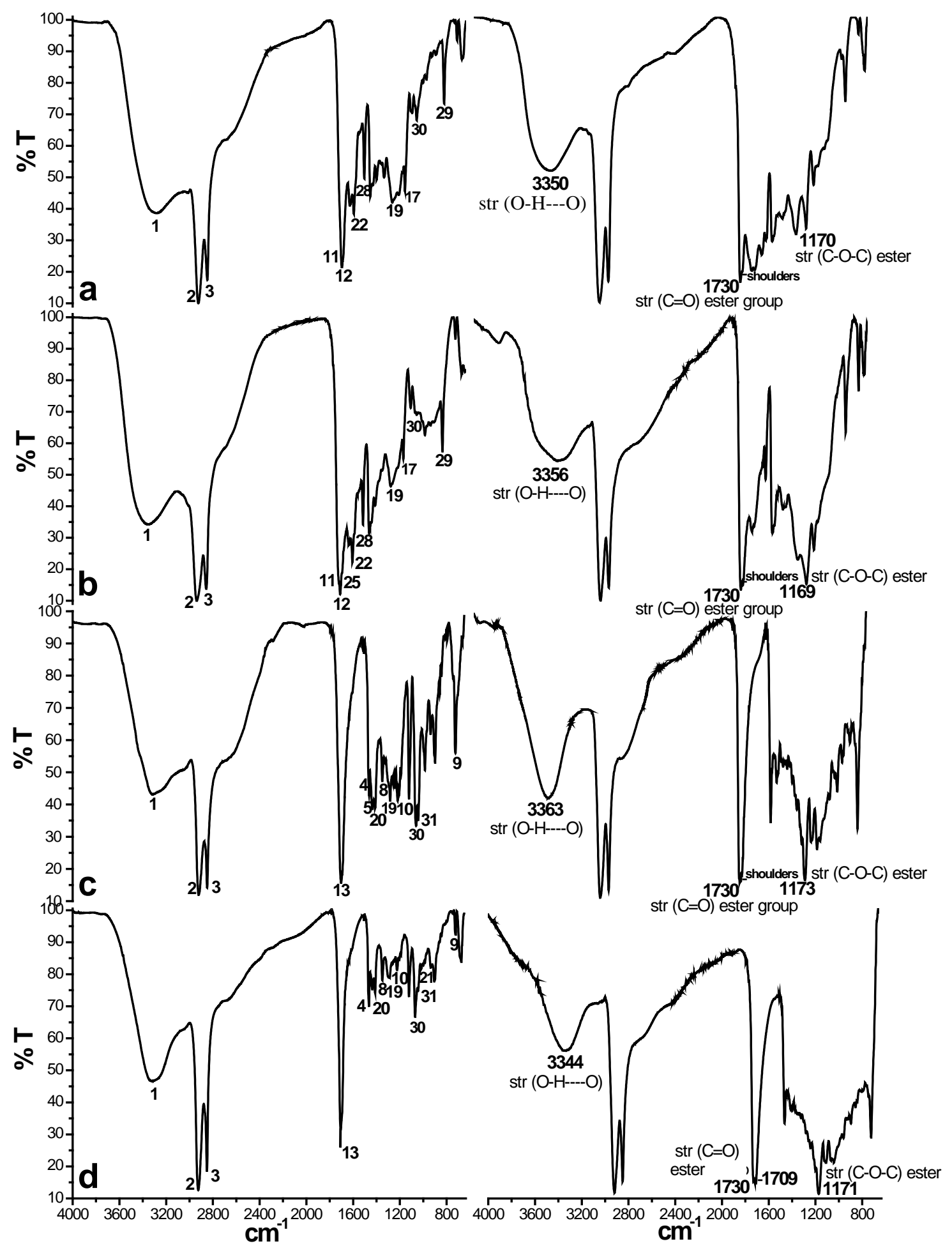

Figure 2. FTIR spectra of raw-cutins (left) and polymerized cutins (right) derived from methods Ac (a), A (b), B (c) and C (d). FTIR spectra were normalized with respect to the $v_{a}\left(\mathrm{CH}_{2}\right)$ asymmetric stretching band. 
Bands at $1660 \mathrm{~cm}^{-1}(\mathrm{v}(\mathrm{C}=\mathrm{O}))$, at $1550 \mathrm{~cm}^{-1}(\delta(\mathrm{N}-\mathrm{H}))$ and other minor bands in the $1100-1500 \mathrm{~cm}^{-1}$ spectral region may be ascribable to proteins [8]. Moreover, for all samples, the two bands at $\sim 1040 \mathrm{~cm}^{-1}$ and $\sim 1060 \mathrm{~cm}^{-1}$ may be ascribable to the bending of primary and secondary hydroxyl groups $(\mathrm{O}-\mathrm{H})$ or the stretching of glycosidic bonds $v(\mathrm{C}-\mathrm{O})$ in polysaccharides. The presence of a certain amount of cellulose was not excluded.

Table 1. Assignments of the most relevant signals in the FTIR spectra of cutin A, Ac, B and C.

\begin{tabular}{|c|c|c|c|c|}
\hline \multicolumn{4}{|c|}{ FTIR / $\mathrm{cm}^{-1}$} & \multirow{3}{*}{ Assignment ${ }^{15}$} \\
\hline \multicolumn{4}{|c|}{ ( ${ }^{\text {a peak name in figure } 2 \text { ) }}$} & \\
\hline Method A & Method Ac & Method B & Method C & \\
\hline $3307 \pm 20(1)^{\mathrm{a}}$ & $3349 \pm 30(1)^{\mathrm{a}}$ & $3300 \pm 40(1)^{\mathrm{a}}$ & $3300 \pm 30(1)^{\mathrm{a}}$ & str $(\mathrm{O}-\mathrm{H}----\mathrm{O})$ \\
\hline $2933 \pm 4(2)^{\mathrm{a}}$ & $2932 \pm 2(2)^{\mathrm{a}}$ & $2917 \pm 4(2)^{\mathrm{a}}$ & $2922 \pm 8(2)^{\mathrm{a}}$ & str asymmetric $\left(\mathrm{CH}_{2}\right)$ \\
\hline $2856 \pm 1(3)^{\mathrm{a}}$ & $2856 \pm 2(3)^{\mathrm{a}}$ & $2848 \pm 2(3)^{\mathrm{a}}$ & $2850 \pm 1(3)^{\mathrm{a}}$ & str symmetric $\left(\mathrm{CH}_{2}\right)$ \\
\hline $1464 \pm 0$ & $1460 \pm 5$ & $1468 \pm 1(4)^{\mathrm{a}}$ & $1463 \pm 0(4)^{\mathrm{a}}$ & \\
\hline $1374 \pm 2$ & $1375 \pm 2$ & $1463 \pm 2(5)^{\mathrm{a}}$ & $1375 \pm 3$ & bend $\left(\mathrm{CH}_{2}\right)$ \\
\hline $724 \pm 0$ & $725 \pm 1$ & $\begin{array}{c}1433 \pm 1 \\
1323 \pm 1(8)^{\mathrm{a}} \\
723 \pm 2 \\
\end{array}$ & $\begin{array}{l}1323 \pm 1(8)^{\mathrm{a}} \\
721 \pm 1(9)^{\mathrm{a}}\end{array}$ & \\
\hline \multicolumn{2}{|c|}{ in overlapping zone } & $1219 \pm 1(10)^{\mathrm{a}}$ & $1221 \pm 2(10)^{\mathrm{a}}$ & str (C-C) chain \\
\hline $1728 \pm 7(11)^{\mathrm{a}}$ & $1726 \pm 3(11)^{\mathrm{a}}$ & - & - & str $(\mathrm{C}=\mathrm{O})$ ester group \\
\hline $1712 \pm 1(12)^{\mathrm{a}}$ & $1712 \pm 1(12)^{\mathrm{a}}$ & - & - & $\operatorname{str}(\mathrm{C}=\mathrm{O}----\mathrm{H}) \mathrm{H}$-bonded ester groups \\
\hline $1703 \pm 0$ & $1701 \pm 1$ & $1702 \pm 0(13)^{\mathrm{a}}$ & $1703 \pm 2(13)^{\mathrm{a}}$ & str $(\mathrm{C}=\mathrm{O})$ free acid group \\
\hline $1693 \pm 1$ & & $1693 \pm 0$ & $1693 \pm 1$ & shoulders on band of $\operatorname{str}(\mathrm{C}=\mathrm{O}----\mathrm{H})$ \\
\hline $1698 \pm 0$ & $1698 \pm 0$ & & $1698 \pm 0$ & H-bonded acid groups \\
\hline $1704 \pm 2$ & & $1706 \pm 1$ & $1707 \pm 2$ & \\
\hline $1170 \pm 0(17)^{\mathrm{a}}$ & $1170 \pm 1(17)^{\mathrm{a}}$ & - & - & str asymmetric (C-O-C) ester \\
\hline $1632 \pm 0$ & $1632 \pm 0$ & - & - & str (C=C phenolic acid) \\
\hline $1277 \pm 1(19)^{\mathrm{a}}$ & $1276 \pm 1(19)^{\mathrm{a}}$ & $1283 \pm 0(19)^{\mathrm{a}}$ & $1286 \pm 2(19)^{\mathrm{a}}$ & $\begin{array}{l}\text { (C-O) stretching asymmetric } \\
\text { (carboxylic acid) }\end{array}$ \\
\hline $\begin{array}{l}1411 \pm 0 \\
937 \pm 0\end{array}$ & $\begin{array}{l}1411 \pm 1 \\
936 \pm 1\end{array}$ & $\begin{array}{c}1411 \pm 1(20)^{\mathrm{a}} \\
936 \pm 0\end{array}$ & $\begin{array}{l}1411 \pm 1(20)^{\mathrm{a}} \\
935 \pm 2(21)^{\mathrm{a}}\end{array}$ & bend O-H (carboxylic acid) \\
\hline $\begin{array}{c}1606 \pm 1(22)^{\mathrm{a}} \\
1588 \pm 1 \\
1454 \pm 1\end{array}$ & $\begin{array}{c}1605 \pm 1(22)^{\mathrm{a}} \\
1587 \pm 0 \\
1453 \pm 0\end{array}$ & - & - & str (C-C aromatic) \\
\hline $1640 \pm 1(25)^{\mathrm{a}}$ & $1638 \pm 2(25)^{\mathrm{a}}$ & - & - & str $(\mathrm{C}=\mathrm{C})$ double bonds \\
\hline $\begin{array}{c}1541 \pm 1 \\
1516 \pm 0(28)^{\mathrm{a}} \\
1559 \pm 2 \\
\end{array}$ & \begin{tabular}{|c|}
$1543 \pm 4$ \\
$1515 \pm 0(28)^{\mathrm{a}}$ \\
$1563 \pm 3$ \\
\end{tabular} & - & $\begin{array}{l}- \\
-\end{array}$ & $\begin{array}{l}\text { str (C-C aromatic conjugated with } \\
\mathrm{C}=\mathrm{C}) \\
\text { in phenolic compounds }\end{array}$ \\
\hline $835 \pm 0(29)^{\mathrm{a}}$ & $835 \pm 1(29)^{\mathrm{a}}$ & - & - & bend oop (C-H and C-C) aromatic \\
\hline $1058 \pm 1(30)^{\mathrm{a}}$ & $1057 \pm 3(30)^{\mathrm{a}}$ & $\begin{array}{l}1060 \pm 0(30)^{\mathrm{a}} \\
1042 \pm 1(31)^{\mathrm{a}}\end{array}$ & $\begin{array}{l}1065 \pm 7(30)^{\mathrm{a}} \\
1042 \pm 2(31)^{\mathrm{a}}\end{array}$ & $\begin{array}{l}\text { bend }(\mathrm{O}-\mathrm{H}) \text { primary and secondary } \\
\text { and possible str }(\mathrm{C}-\mathrm{O}) \\
\text { polysaccharides }\end{array}$ \\
\hline
\end{tabular}

\subsection{Monomer composition by GC-MS analysis}

GC-MS analysis was carried out to identify the cutin monomers (table 2); in particular, the soluble fraction in $\mathrm{CHCl}_{2}$ was analysed (section 2.5).

The major monomers in all cutin samples (methods A, Ac, B and C) were 10,16-dihydroxy hexadecanoic acid isomers that commonly exist in tomato cutin polymers [12].

The principal peak in GC-MS chromatograms in the cutin samples corresponded to 10,16-dihydroxy hexadecanoic acid, amounting to $68 \pm 7 \%$ in cutin Ac, $62 \pm 15 \%$ in cutin A, $82 \pm 4 \%$ in cutin B and $82 \pm 4 \%$ in cutin $\mathrm{C}$. Indeed, the mass spectrum (at 22 minutes retention time) presented diagnostic ions of long-chain methyl ester of 10,16-diOH-16:0. The major cleavage ions were at $275 \mathrm{~m} / \mathrm{z}$ and $171 \mathrm{~m} / \mathrm{z}$, and the rearrangement ions were at $169 \mathrm{~m} / \mathrm{z}$ and $273 \mathrm{~m} / \mathrm{z}$, with a further loss occurring at $129 \mathrm{~m} / \mathrm{z}$. The main fragmentation occurred to the oxygen atom in beta because the hydroxy group occupied a central position in the molecule [17].

Several isomers (different methyl and/or TMS derivatives) of 10,16-dihydroxyhexadecanoic acid were also found in all samples according to previous studies [13] (table 2).

Other isomers identified were 9,16-dihydroxyhexadecanoic acid, 8,16-diOH-16:0 and 7,16-diOH-16:0 isomers, which were found in smaller amounts in tomato cutin [18]. 
The monohydroxy acids, mainly $\omega$-hydroxy acid (16-OH-16:0), amounting to $2 \%$ in cutin A and Ac, 6\% in cutin B and $\sim 5 \%$ in cutin C (table 2). A small quantity of tri-hydroxy acids was also identified $(<0.4 \%)$.

Furthermore, C18-fatty acids and epoxy-hydroxy monomers were identified. Small amounts of suberin-like $\alpha, \omega$-diacids were found in all samples. Saturated acids and some unsaturated acids (e.g. oleic acid) were identified (1-3\%). Moreover, mono or di-unsaturated fatty acids were mainly identified in chromatograms of cutins derived from method A ( 5\%) and Ac ( 4 \%). Unsaturated compounds occurred in very small quantities ( 1\%,) in only a few of the cutin samples obtained from method B; and not at all in the cutin samples derived from the $\mathrm{H}_{2} \mathrm{O}_{2}-$ route.

Aromatic compounds were found in quite large quantities in the cutin extracted using methods A and Ac (5$6 \%$ ). The aromatic compounds that commonly found in the cutin chromatograms were phenolic compounds, derivatives of cinnamic acid (e.g. octyl 4-methoxycinnamate), p-coumaric acid and its isomers; and derivatives of hydroxybenzoic acid. It is known that these species generally exist in an esterified state in the cutin polyesters of the tomato cuticle [19]. A very small amount $(<0.2 \%)$ of aromatics were found in cutin samples obtained from method B, while they were entirely absent from the cutin derived by means of the hydrogen peroxide route.

Cutin monomer yields were given as the percentage of depolymerized material obtained by $\mathrm{NaOMe}$ methanolysis that was found to be soluble in $\mathrm{CHCl}_{2}$. The higher monomeric yields for samples $\mathrm{B}$ and $\mathrm{C}$ over cutins $\mathrm{A}$ and Ac can be attributed to their isolation processes. The monomeric yields amounted to $81 \pm 5 \%$ (cutin A), 83 $\pm 6 \%$ (cutin Ac), $92 \pm 6 \%$ (cutin B) and $96 \pm 4 \%$ (cutin C).

\subsection{GPC analysis}

GPC analysis was carried out to assess polydispersity and to enable comparison between the extracts. This analysis indicated that the sample with the largest molecular weight was cutin $A\left(M_{w} \sim 7000 \mathrm{Da}, \mathrm{M}_{\mathrm{n}} \sim 910 \mathrm{Da}\right)$ with a $\mathrm{P}$ value of 7.7. The Ac sample ( $\left.\mathrm{M}_{\mathrm{w}} \sim 6800 \mathrm{Da}, \mathrm{M}_{\mathrm{n}} \sim 750 \mathrm{Da}\right)$ was slightly lower in molecular weight than cutin $\mathrm{A}$, but was characterized by by higher molecular weight and polydispersity $(\mathrm{P} \sim 9.1)$. The molecular weights of the cutins obtained using methods B and C were similar $\left(\mathrm{M}_{\mathrm{w}} \sim 385 \mathrm{Da}\right)$.

The chromatograms of cutin from methods B and C showed a sharp and intense peak at 72 minutes corresponding to the molecular weight of 10,16-dihydroxyhexadecanoic acid in dimeric form, and a weak signal at 65 minutes (figure 4f). The GPC chromatograms of samples A and Ac showed a broad band between 45 and 65 minutes, which was absent in the GPC chromatograms of samples B and C, and corresponded to a large hydrodynamic size $\left(M_{\mathrm{w}} \approx 23000\right.$ Da and $\left.M_{\mathrm{n}} \approx 19000 \mathrm{Da}\right)$.

\subsection{Thermogravimetric analysis (TGA)}

The A and Ac cutins had a gummy appearance, probably due to their tendency for water uptake. Cutins produced using methods A and Ac with different levels of moisture content (ranging from 62\% to 98\%) were subjected to TGA analysis to demonstrate this tendency, and to study the influence of water on the thermal weight loss of oligomers.

The thermogravimetric plot profiles of cutins A and Ac were very similar, with both samples showing weight loss in different stages (at least 5).

The first weight loss in the TGA profiles (peak 1 in DTG curves) of cutins A and Ac (DR up to 80\%) is due to evaporation of surface water (figures $3 a$ and $3 b$ ).

The TGA profiles of cutin A showed that the mass loss at $113 \pm 3^{\circ} \mathrm{C}$ (peak 2 in DTG curve, figure 3a) decreased as DR increased. Similar behaviour was observed in cutin Ac. This correlation suggests that the weight loss was due primarily to water uptake by the several hydroxyl cutin groups, which were acting as water coordination sites. The characteristic appearance of cutins A and Ac could been explained by the plasticizing effect of adsorbed water.

The DTG profile of cutin Ac showed the loss of bound moisture in two different steps: a splitting of peak 2 (at $\sim 97^{\circ} \mathrm{C}$ and at $\sim 109^{\circ} \mathrm{C}$ ) occurred. This behaviour could be due to the sample's high degree of heterogeneity.

Figure 3b shows the TGA profile of cutin A with a DR of $98( \pm 1) \%$ appearing as a very cohesive mass. A shift in the second weight loss (amounting to $2 \%$ ) occurred at $132 \pm 3{ }^{\circ} \mathrm{C}$. Conversely, peaks 3,4 and 5 in the DTG curve did not correlate with the samples’ humidity levels (figure $3 \mathrm{~b}$ ).

Figures 3c and 3d illustrate the thermogravimetric plots of cutins B and C. Both samples were conditioned in a controlled humidity chamber reaching a dry residue of $98( \pm 1) \%$. These plots showed a two-stage weight loss commonly seen in the TGA patterns of fatty acids [20]. Cutins B and C were thermally stable up to $220-230^{\circ} \mathrm{C}$, showing weight losses at a maximum decomposition temperature $\left(\mathrm{Td}\right.$,max) of $268( \pm 6)^{\circ} \mathrm{C}$ and $263( \pm 4)^{\circ} \mathrm{C}$ respectively). This weight loss is mostly associated with the dehydration and decarboxylation processes of the hydroxyacids [21]. Subsequently, these samples had a second stage of decomposition in multiple steps (between $396^{\circ} \mathrm{C}$ and $494^{\circ} \mathrm{C}$ ), accounting for approximately $73 \%$.

All samples (A, Ac, B and C) showed the aforementioned multi-step weight loss, this behaviour is commonly observed in biomass derived-samples [22]. This revealed the samples under analysis to be complex mixtures of different fatty acids, according to GC-MS analysis (table 2). This last decomposition stage could be attributed to the fragmentation of the aliphatic chain of fatty acids and oligomers [20,23]. 
Table 2. Main monomers obtained from TMS derivatised and methanolysates cutins derived from methods Ac, A, $\mathrm{B}$ and $\mathrm{C}$, identified by GC-MS analysis.

\begin{tabular}{|c|c|c|c|c|c|}
\hline \multirow[t]{2}{*}{ Method } & \multirow[t]{2}{*}{ Identification } & \multirow[t]{2}{*}{$\begin{array}{l}\text { Retention } \\
\text { time (min) }\end{array}$} & \multicolumn{2}{|c|}{$\begin{array}{c}\text { Certainty } \\
\text { of identification }\end{array}$} & \multirow[t]{2}{*}{$\begin{array}{c}\text { Composition } \\
\text { (\%) }\end{array}$} \\
\hline & & & F.M & probability(\%) & \\
\hline & Hydroxyacids & & & & \\
\hline Ac & \multirow{4}{*}{ 10,16-dihydroxyhexadecanoic acid } & 22.31 & 846 & 94 & $68.3 \pm 7.0$ \\
\hline$A$ & & 22.36 & 836 & 95 & $62.4 \pm 15.1$ \\
\hline$B$ & & 22.23 & 824 & 93 & $82.2 \pm 3.7$ \\
\hline$C$ & & 22.23 & 751 & 88 & $82.0 \pm 5.6$ \\
\hline B & \multirow{4}{*}{$\begin{array}{c}\text { Isomers of } 10,16- \\
\text { dihydroxyhexadecanoic acid }\end{array}$} & 21.70 & 721 & 84 & $1.9 \pm 0.7$ \\
\hline & & 23.76 & 717 & 81 & $1.5 \pm 0.4$ \\
\hline$C$ & & 21.24 & 658 & 48 & $1.7 \pm 0.1$ \\
\hline & & 23.75 & 715 & 81 & $1.3 \pm 0.8$ \\
\hline$C$ & 9,10-dihydroxyoctadecanoic acid & 21.97 & 557 & 10 & $0.8 \pm 0.3$ \\
\hline Ac & \multirow[t]{4}{*}{ 16-Hydroxyhexadecanoic acid } & 20.46 & 891 & 98 & $2.4 \pm 0.3$ \\
\hline$A$ & & 20.52 & 871 & 96 & $2.2 \pm 0.5$ \\
\hline B & & 20.41 & 901 & 98 & $5.6 \pm 0.9$ \\
\hline$C$ & & 20.41 & 897 & 98 & $5.0 \pm 2.0$ \\
\hline Ac & \multirow{4}{*}{$\begin{array}{c}\text { 9,10-epoxy-18-hydroxyoctadecanoic } \\
\text { acid } \\
\text { or } \\
\text { 18-hydroxyoctadec-9-enoic acid }\end{array}$} & 23.01 & 606 & 23 & $1.7 \pm 0.4$ \\
\hline$A$ & & 23.15 & 590 & 18 & $0.9 \pm 0.6$ \\
\hline B & & 22.34 & 615 & 7 & $2.1 \pm 0.7$ \\
\hline \multirow[t]{2}{*}{$C$} & & 22.35 & 579 & 10 & $0.9 \pm 0.3$ \\
\hline & Alkanoic acids & & & & \\
\hline Ac & \multirow[t]{4}{*}{ Hexadecanoic acid } & 15.52 & 898 & 54 & $1.6 \pm 0.4$ \\
\hline$A$ & & 15.53 & 861 & 44 & $2.0 \pm 0.7$ \\
\hline B & & 15.32 & 908 & 68 & $1.0 \pm 0.5$ \\
\hline$C$ & & 15.32 & 888 & 65 & $1.5 \pm 0.9$ \\
\hline$C$ & Octadecanoic acid & 18.53 & 893 & 70 & $0.8 \pm 0.0$ \\
\hline Ac & \multirow{4}{*}{$\begin{array}{l}\text { Decanedioic acid } \\
\text { (sebacic acid) }\end{array}$} & 23.14 & 605 & 19 & $1.9 \pm 0.8$ \\
\hline$A$ & & 23.13 & 608 & 24 & $1.8 \pm 0.9$ \\
\hline$B$ & & 23.02 & 625 & 40 & $3.7 \pm 3.2$ \\
\hline$C$ & & 23.02 & 609 & 35 & $3.6 \pm 3.5$ \\
\hline$C$ & Isomer of sebacic acid & 21.51 & 573 & 8 & $0.6 \pm 0.1$ \\
\hline Ac & \multirow[t]{2}{*}{ Docosanedioic acid } & 20.21 & 658 & 31 & $1.1 \pm 0.1$ \\
\hline \multirow[t]{2}{*}{$A$} & & 20.26 & 791 & 26 & $0.7 \pm 0.0$ \\
\hline & Unsaturated acids & & & & \\
\hline Ac & \multirow[t]{2}{*}{ 18-hydroxyoctadec-9-enoic acid } & 21.07 & 591 & 17 & $1.6 \pm 0.4$ \\
\hline$A$ & & 21.11 & 578 & 15 & $1.4 \pm 0.2$ \\
\hline Ac & \multirow[t]{2}{*}{ 9,12-octadecandienoic acid } & 18.13 & 840 & 21 & $2.2 \pm 0.7$ \\
\hline \multirow[t]{2}{*}{$A$} & & 18.18 & 920 & 37 & $3.6 \pm 1.2$ \\
\hline & Aromatics & & & & \\
\hline Ac & \multirow{2}{*}{$\begin{array}{c}\text { (E)-3-(4-hydroxyphenyl)-2-propenoic } \\
\text { acid } \\
\text { (p-coumaric acid })\end{array}$} & 12.96 & 975 & 98 & $1.7 \pm 0.8$ \\
\hline$A$ & & 12.97 & 930 & 91 & $2.0 \pm 0.5$ \\
\hline Ac & \multirow[t]{2}{*}{ Isomer of p-coumaric acid } & 15.71 & 901 & 94 & $3.1 \pm 0.1$ \\
\hline$A$ & & 15.75 & 897 & 88 & $2.6 \pm 0.7$ \\
\hline Ac & \multirow[t]{2}{*}{ 1,4-Benzenedicarboxylic acid } & 10.28 & 857 & 90 & $0.2 \pm 0.1$ \\
\hline$A$ & & 10.29 & 860 & 97 & $0.4 \pm 0.0$ \\
\hline
\end{tabular}

Samples B and C showed weight loss at approx. $260^{\circ} \mathrm{C}$ (peak 4 in the DTG curves figure 3), which was greater (10 $\pm 1 \%$ and $14 \pm 3 \%$ respectively) than samples $A(5 \pm 2 \%)$ and Ac $(7 \pm 1 \%)$. As stated above, this step was due to processes of hydroxyacid dehydration and decarboxylation [21] and is therefore related to the degree of polymerisation and crosslinking in different materials. The cutin samples treated in the oven at $150^{\circ} \mathrm{C}$ were characterized by TGA in order to confirm this hypothesis. The treated samples reached a certain degree of polymerisation, as confirmed by the presence of bands in their FT-IR spectra (figure 2-right) at $1730 \mathrm{~cm}^{-1}$ and at $1170 \mathrm{~cm}^{-1}$, ascribed to $v(\mathrm{C}=\mathrm{O})$ and $v(\mathrm{C}-\mathrm{O}-\mathrm{C})$ ester stretches. Figures $2 \mathrm{~d}$ and $3 \mathrm{~d}$ illustrate the FT-IR spectrum and 
TGA plot of sample C, which was treated for $4 \mathrm{~h}$ in the oven, because longer treatments cause product degradation, as was confirmed by FT-IR analysis; in fact, a broad band appears between 1600 and $1650 \mathrm{~cm}^{-1}$ for longer reaction times. This behaviour is probably due to a dehydration process involving the secondary free-hydroxyls. All treated samples had very low weight losses (about $2-3 \%$ at most) at a Td,max of $260^{\circ} \mathrm{C}$, in comparison with the untreated samples. The solid residue remaining at $600^{\circ} \mathrm{C}$ was within the same range (between $13-15 \%$ ) for all samples.

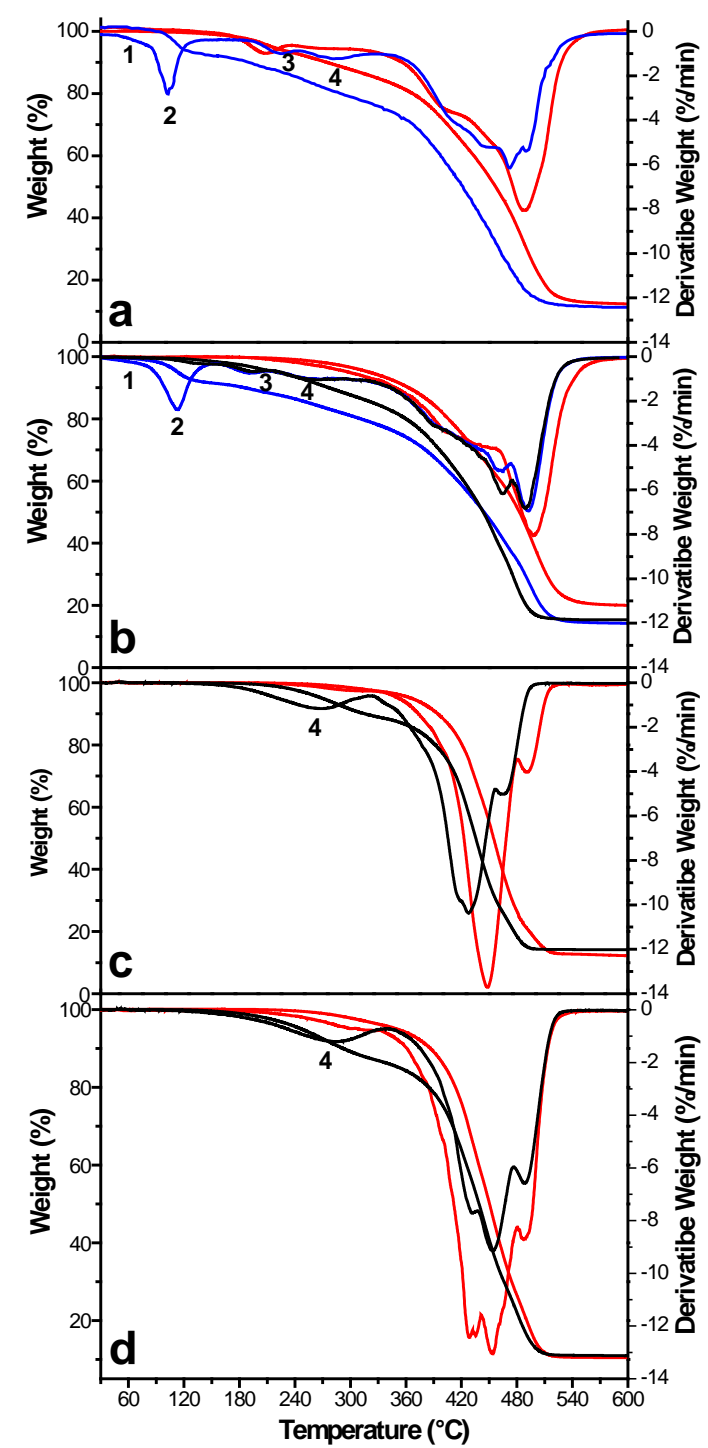

Figure 3. TGA and DTG curves of polymerized cutin (red line) and raw cutin, where the dry residue amounts to 87\% (blue lines) in the samples Ac (a) and A (b); 98\% (black lines) in the samples A (b), B (c) and C (d).

\subsection{Differential scanning calorimetry (DSC)}

A first set of DSC experiments was carried out in order to monitor the influence of water on thermal transitions in oligomers. For this purpose, cutin samples from methods A and Ac with different levels of moisture content (ranging between 62\% and 98\%) were studied using sample containers with pierced lids.

The cutins (A and Ac) with low DR (up to 65\%) showed an endothermic peak at just below the freezing point of water in the first heating cycle. This transition indicates the presence of freezable water in the sample.

The glass transition temperatures were evaluated only for dried samples (RS at least $76 \%$ ), because the aforementioned transition interferes with the Tg in the thermograms of cutins with higher water content. The glass transition temperatures of dried cutin samples were found to be $\sim-23^{\circ} \mathrm{C}(\mathrm{Tg}, \mathrm{m})$ in the first heating cycle. In the second heating cycle, a Tg,m shift of about $10-15^{\circ} \mathrm{C}$ occurred, owing to dehydration: higher oligomer dehydration Tg was associated with reduced hydrocarbon chain mobility [24]. 
The aforementioned results related to cutins A and Ac suggested the cutin contained both freezable water (not bound moisture) and bound moisture. Bound moisture has a plasticising effect on cutin, as reported in amorphous polymers of a different nature [25].

Figure 4c shows the thermogram of sample A completely dried (DR $98 \pm 2 \%$ ).

The Tg,m $\left(-10 \pm 0{ }^{\circ} \mathrm{C}\right)$, Tg, ONSET $\left(-15 \pm 1{ }^{\circ} \mathrm{C}\right)$ and heat capacity $\Delta \mathrm{Cp}\left(0.41 \pm 0.03 \mathrm{~J} / \mathrm{g} \cdot{ }^{\circ} \mathrm{C}\right)$ values associated with glass transition were found to be in accordance with previous literature on cutin from blueberries [26] and tomatoes [21].

The thermogram of wholly dehydrated Ac cutin showed an endothermic peak at $\sim 21^{\circ} \mathrm{C}(\Delta \mathrm{H}=4-6 \mathrm{~J} / \mathrm{g})$ and a lower glass transition temperature than cutin A. The Tg,m and Tg,onset of cutin Ac were $\sim-21^{\circ} \mathrm{C}$ and $\sim 26^{\circ} \mathrm{C}$ respectively.

DSC analysis of cutins from methods A and Ac was then performed using O-ring sealed sample pans. The samples were equilibrated to an equivalent humidity range. DSC data on cutin A from the first heating cycle revealed three low endothermic events at onset temperatures of $24 \pm(1)^{\circ} \mathrm{C}, 37 \pm(3)^{\circ} \mathrm{C}$ and $57 \pm(0)^{\circ} \mathrm{C}$. The enthalpies associated with these transitions were $\sim 1 \mathrm{~J} / \mathrm{g}, 2 \mathrm{~J} / \mathrm{g}$ and $0.2 \mathrm{~J} / \mathrm{g}$ respectively. In addition, an exothermic event at $23 \pm 1{ }^{\circ} \mathrm{C}(\Delta \mathrm{H} \sim-3 \mathrm{~J} / \mathrm{g})$ occurred in the cooling cycle, with a single endothermic event at $39 \pm 0{ }^{\circ} \mathrm{C}(\Delta \mathrm{H} \sim 3$ $\mathrm{J} / \mathrm{g}$ ) in the last heating cycle (figure $4 \mathrm{~b}$ ).

The endothermic transitions observed in the cutin could be attributed to the melting of aliphatic moieties such as the wax-like material in the biopolymer (e.g. fatty acids, alcohols and n-alkanes), according to earlier literature. Luque et al. [27] reported the melting of cuticular waxes in tomato cuticle at $\sim 30^{\circ} \mathrm{C}$. In the DSC re-run, the broad melting transition ranging from $30-60^{\circ}$ indicates that the nature of these transitions, which are associated with the fusion of wax or oil like materials with a low degree of crystallinity, is not entirely reversible. These species form a melt that solidifies into a glass state upon cooling, as reported elsewhere [28].

The DSC thermogram of cutin Ac revealed an endothermic event with an onset temperature of $\sim 50^{\circ} \mathrm{C}(\Delta \mathrm{H} \sim 40$ $\mathrm{J} / \mathrm{g})$ in the first heating cycle and $\sim 20^{\circ} \mathrm{C}(\Delta \mathrm{H} \sim 15 \mathrm{~J} / \mathrm{g})$ in the subsequent heating cycle (figure $\left.4 \mathrm{~b}\right)$.

A significant variation in enthalpy was associated with the melting of wax mixtures in cutin $\mathrm{A}_{\mathrm{C}}$. This behaviour suggests that cutin $A_{C}$ has a higher degree of heterogeneity than cutin $A$; in fact the Ac samples were obtained by means of the co-precipitation of all extracted fractions, bypassing any purification of the alkaline solution (figure 1).

The thermal profiles of cutins B and C were very similar and no glass transition was observed in either sample. Figure 4d illustrates the DSC thermogram of cutin B (DR $98 \pm 2 \%$ ).

DSC data of samples B and C from the first heat segment of the cycle showed multiple endothermic peaks ranging from $50^{\circ} \mathrm{C}$ to $80^{\circ} \mathrm{C}$. This melting peak shape is frequently observed in multi-component mixtures formed by fatty acids and oils [29]. The enthalpies of transition were $143 \pm 3 \mathrm{~J} / \mathrm{g}$ (cutin B) and $220 \pm 10 \mathrm{~J} / \mathrm{g}$ (cutin B).

In the second heating cycle the samples showed a melting peak with a maximum of $37 \pm 1{ }^{\circ} \mathrm{C}$ and a second multi-step peak at $\sim 60^{\circ} \mathrm{C}$. Between these two endothermic transitions, an exothermic peak was observed at $39 \pm 0$ ${ }^{\circ} \mathrm{C}$ and $43 \pm 2{ }^{\circ} \mathrm{C}$ in cutin $\mathrm{B}$ and $\mathrm{C}$ respectively. An endothermic peak and a subsequent exothermic peak were related to the slow solid-solid transition of metastable crystals, probably formed during the first heating run- The solid-solid transitions (in particular the enantiotropic transitions) gave rise to peaks of different shapes, the like of which are frequently observed in organic compounds as well as in fatty acids and triglycerides. The second warming cycle seemed to trigger a restructuring of the sample, and the exothermic peak indicates the crystallization of a more stable form at a temperature immediately below the melting temperature [28].

The B and C samples crystallized during the cooling cycle (figure 4d). Crystallization occurred at onset temperatures of $27 \pm 1^{\circ} \mathrm{C}$ (cutin $\mathrm{B}$ ) and $25 \pm 0^{\circ} \mathrm{C}$ (cutin C) and the enthalpies of transition were $-73 \pm 3 \mathrm{~J} / \mathrm{g}$ (cutin B) and $-55 \pm 2 \mathrm{~J} / \mathrm{g}$ (cutin C).

The crystallization temperatures of cutins B and $\mathrm{C}$ are characteristic of long chain fatty acids and oils [30], and did not shift significantly in the DSC re-runs. The well-defined shape of the crystallization peaks may be indicative of highly crystalline structures with minimal branching [29].

\subsection{Solubility assay}

The solubility of each material was evaluated in an alcoholic medium (ethanol), glycol (butyl glycol), acetate (Dowanol PMA), ketone (MIBK), ether (THF) and chloroform.

The $\mathrm{A}$ and $\mathrm{A}_{\mathrm{C}}$ samples were soluble in ethanol $\left(\sim 40 \mathrm{~g} / \mathrm{L}\right.$, at $\left.25^{\circ} \mathrm{C}\right)$, but scarcely compatible with other organic solvents tested at ambient temperature. The $\mathrm{A}$ and $\mathrm{A}_{\mathrm{C}}$ samples were freely soluble in butyl glycol and Dowanol PMA at $\sim 60^{\circ} \mathrm{C}$, and in $\mathrm{MIBK}$ at $90^{\circ} \mathrm{C}$, resulting in clear resins.

The cutin obtained from method B was soluble in ethanol $\left(\sim 48 \mathrm{~g} / \mathrm{L}\right.$, at $\left.25^{\circ} \mathrm{C}\right)$ and in THF $\left(\sim 72 \mathrm{~g} / \mathrm{L}\right.$ at $\left.25^{\circ} \mathrm{C}\right)$, but sparingly soluble in Dowanol PMA and MIBK. The solubility of cutin C in butyl glycol was $100 \mathrm{~g} / \mathrm{L}$ at $60^{\circ} \mathrm{C}$.

Cutin C was soluble in hot water and ethanol $\left(\sim 36 \mathrm{~g} / \mathrm{L}\right.$, at $\left.25^{\circ} \mathrm{C}\right)$ and sparingly soluble in THF, Dowanol PMA and MIBK, even at high temperatures. The solubility of cutin $\mathrm{C}$ in butyl glycol was $\sim 15 \mathrm{~g} / \mathrm{L}$ at $60^{\circ} \mathrm{C}$. 
In line with previous studies on the solubility of long chain hydroxyacids [31], all the cutins under analysis (A, Ac, B and C) were practically insoluble in chloroform.
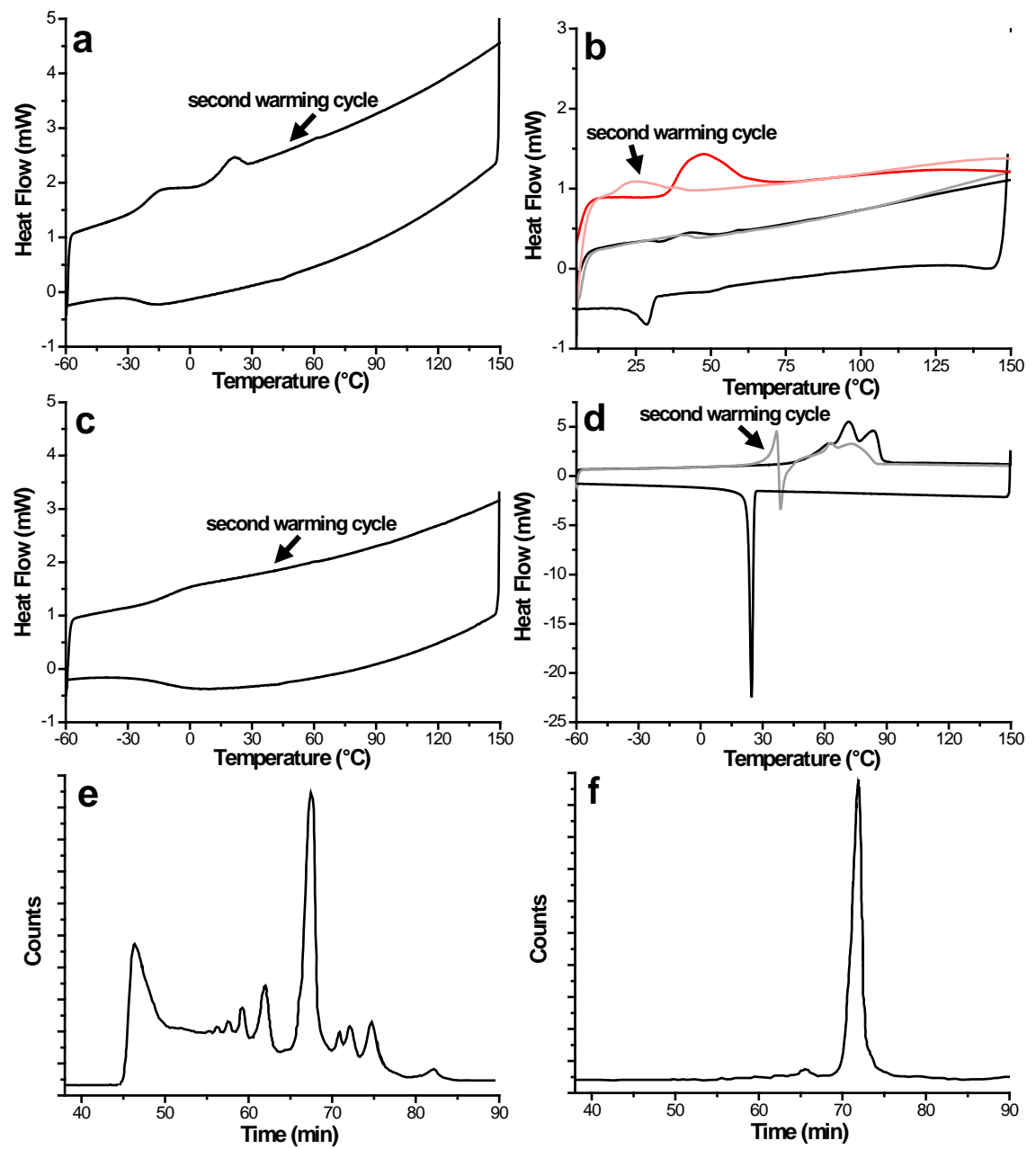

Figure 4. DSC thermograms of samples Ac (a), A (c), B (d) in pans with pierced lids; (b) comparison between cutin Ac (red line) and A (black line) both in sealed pans. GPC chromatograms for samples A (e) and B (f).

\section{Conclusions}

Effective isolation of cutin from tomato peels has been demonstrated by means of alkaline hydrolysis, hydrogen peroxide-assisted hydrolysis (the $\mathrm{NaOH} / \mathrm{H}_{2} \mathrm{O}_{2}$ route), and selective precipitation of sodium carboxylates.

Indeed, GC-MS analysis demonstrated that 10,16-dihydroxyhexadecanoic acid, the principal component of tomato cutin, was the main compound extracted by all procedures, with a monomeric yield ranging between $81 \%$ and $96 \%$.

Extracts showed very different characteristics depending on the extraction method used. Indeed, the gum-like products obtained from methods A and Ac had the appearance of a sticky mass, probably as a result of the intermolecular hydrogen bonding and higher molecular weights revealed by GPC analysis.

The solubility assay revealed all studied samples (A, Ac, B and C) to be insoluble in chloroform, and soluble in ethanol and butyl glycol.

TGA and DSC analysis revealed several differences between the gum-like products (cutins A and Ac) and the crystalline products (cutins B and C). DSC thermograms of cutins A and Ac revealed glass transition occurring below room temperature, as well as the presence of bound moisture exerting a plasticising effect, as is also seen in amorphous polymers.

The DSC profile of cutins $\mathrm{B}$ and $\mathrm{C}$ showed multiple melting peaks ranging between $50-80^{\circ} \mathrm{C}$, and an exothermic peak in the cooling cycles with an onset temperature of $\sim 27^{\circ} \mathrm{C}$, as is commonly observed in the DSC profiles of fatty acids. 
Method B and, in particular, the method using hydrogen peroxide-assisted hydrolysis (method C) produced a purer extract and a greater degree of tomato cutin depolymerisation than methods A and Ac, as revealed by FTIR, GPC and GC-MS analysis, although the reaction yields were lower.

Method B could serve as a simple and cheap alternative to the hydrogen peroxide-assisted route.

Although the $\mathrm{NaOH} / \mathrm{H}_{2} \mathrm{O}_{2}$ and carboxylate routes resulted in purer products with lower molecular-weight and polydispersity, the superior reaction yields and strong organic-solvent compatibility of the gummy mass obtained from simple alkaline hydrolysis point to this latter product as the most promising raw material for bio-resin preparation.

\section{Acknowledgement}

Research activities carried out within the BIOCOPACPLUS project, funded under LIFE+ Environment Policy and Governance project application (Grant Agreement No. LIFE13 ENV/IT/000590).

\section{References}

[1] Boriss H, Brunke H. Processed tomatoes profile. Agricultural Marketing Resource CenterWeb. http://www.agmrc.org/commodities_products/vegetables/ processed_tomatoes_profile.cfm. 2015.

[2] Ventura MR, Pieltain MC. Evaluation of tomato crop by-products as feed for goats. Anim Feed Sci Tech, 2009:271.

[3] Cuccolini S, Aldini A, Visai L. Environmentally friendly lycopene purification from tomato peel waste: enzymatic assisted aqueous extraction. J Agric Food Chem, 2013:1646.

[4] Heredia A. Biophysical and biochemical characteristics of cutin, a plant barrier biopolymer. Biochim Biophys Acta, 2003:1.

[5] Bunker SP, Woo RP. Synthesis and characterization of monomers and polymers for adhesives from methyl oleate. Polym Chem, 2002:451.

[6] Koskimies S, Hulkko J, Pitkänen P. Method for the manufacture of oligo- and polyesters from a mixture of carboxylic acid obtained from suberin and/or cutin and use thereof. US 20110319504 A1. 2011. https://patents.google.com/patent/US20110319504.

[7] Osman SF, Irwin P, Fett WF. Preparation, isolation, and characterization of cutin monomers and oligomers from tomato peels. J Agric Food Chem, 1999:799.

[8] Jiang F, Hsieh YL. Cellulose nanocrystal isolation from tomato peels and assembled nanofibers. Carbohydr Polym, 2015:60.

[9] Gray MK. Alkaline hydrogen peroxide pretreatment for its use in an on-farm bioprocessing facility. Theses and Dissertations--Biosystems and Agricultural Engineering, 2013:18. http://uknowledge.uky.edu/bae_etds/18.

[10] Savy D, Piccolo A. Physical-chemical characteristics of lignin separated from biomasses for secondgeneration ethanol. Biomass Bioenerg, 2014:58.

[11] Montanari A, Bolzoni , Cigognini IM, De la Torre Carreras R. Tomato bio-based lacquer for sustainable metal packaging. Agro Food Industry Hi Tech, 2014:44.

[12] Graca J, Lamosa P. Linear and branched poly( $\omega$-hydroxyacid)esters in Plant Cutins. J Agric Food Chem, 2010:9666.

[13] Järvinen R, Kaimenen M, Kallio H. Cutin Composition of selected northern berries and seed. Food Chem, 2010:137.

[14] Moore JC. A new method for molecular weight distribution of high polymers. J Polym Sci, 1964:835.

[15] Heredia-Guerrero JA, Benìtez JJ, Domìnguez E. Infrared and Raman spectroscopic features of plant cuticles: a review. Front Plant Sci, 2014:1.

[16] Ramírez FJ, Luque P., Heredia A, Bukovac MJ. Fourier transform IR of enzymatically isolated tomato fruit cuticular membrane. Biopolymers, 1992: 1425.

[17] Nicolaides N, Soukup VG, Ruth EC. Mass spectrometry fragmentation patterns of the acetoxy and trimethylsilyl derivatives of all the positional isomers of the methyl hydroxypalmitates. Biomed Mass Spectrom, 1983:441.

[18] Holloway PJ, Deas AHB. Occurrence of positional isomers of dihydroxyhexadecanoic acid in plant cutins and suberins. Phytochem, 1971:2781.

[19] Tohge T, Alseekh S, Fernie AR. Review paper on the regulation and function of secondary metabolism during fruit development and ripening. J Exp Bot, 2014:4599.

[20] García-Zapateiro LA, Franco JM, Valencia C. Chemical, thermal and viscous characterization of high-oleic sunflower and olive pomace acid oils and derived estolides. Grasas Aceites, 2013:497.

[21] Benítez JJ, Heredia-Guerrero JA. Polyhydroxyester films obtained by non-catalyzed melt-polycondensation of natural occurring fatty polyhydroxyacids. Front Mater, 2015:59. 
[22] Liang S, McDonald AG. Chemical and thermal characterization of potato peel waste and its fermentation residue as potential resources for biofuel and bioproducts production. J Agric Food Chem, 2014:8421.

[23] Sutton GJ, Tighe BJ. Poly- $\alpha$-ester degradation studies. J Polymer sci, 1973:1069.

[24] Matas AJ, Cuartero J, Heredia A. Phasetransitions in the biopolyestercutin isolated from tomato fruit cuticles. Thermochimica acta 2004:165.

[25] Hernàndez RJ, Gianci JR, Grulke EA. The sorption of water vapor by an amorphous polyamide. Journal of Membrane Science, 1992:187.

[26] Díaz P, Henríquez O. Thermal transitions of pulp and cuticle of blueberries. Thermochimica Acta, 2011:56.

[27] Luque P, Heredia A. The glassy state in isolated cuticles: differential scanning calorimetry of tomato fruit cuticular membranes. Plant Phys Biochem, 1997:251.

[28] Small DM. Handbook of Lipid Research. Plenum Press. 1966.

[29] Gomez-Patino MB, Gutièrrez-Salgado DY. Polymerization of 10,16-dihydroxyhexadecanoic acid main monomer of tomato cuticle using the Lewis acidic ionic liquid choline chloride· $2 \mathrm{ZnCl} 2$. Frontiers in Materials, 2015:67.

[30] Ajithkumar G, Jayadas NH, Bhasi M. Analysis of the pour point of coconut oil as a lubricant base stock using differential scanning calorimetry. Lubrication Science, 2009:1.

[31] Bhattacharya R. Properties of aleuritic acid. J Soc Chem Ind, 1935:285. 